\title{
OPEN Noble-Metal based Metallic Glasses as Highly Catalytic Materials for Hydrogen Oxidation Reaction in Fuel Cells
}

Received: 17 January 2019

Published online: 20 August 2019

\begin{abstract}
Vahid Hasannaeimi \& Sundeep Mukherjee
Electro-catalyst design with superior performance and reduced precious metal content (compared to state-of-the-art $\mathrm{Pt} / \mathrm{C}$ ) has been a challenge in proton exchange membrane fuel cells, preventing their widespread adoption. Metallic glasses have recently shown promising performance and large electrochemical surface area in catalytic reactions. The electro-catalytic behavior of recently developed Pt-, Pd-, and Pt/Pd-based metallic glasses was evaluated in this study using scanning electrochemical microscopy. The influence of chemistry and electronic structure on catalytic behavior was studied using scanning kelvin probe technique. The work function for the metallic glasses was lower by $75 \mathrm{mV}$ to $175 \mathrm{mV}$ compared to pure Pt. This resulted in higher catalytic activity for the amorphous alloys, which was attributed to the ease of charge transfer on the surface. The binding energy for the metallic glasses, measured using X-ray photoelectron spectroscopy, was higher by $0.2 \mathrm{eV}$ to $0.4 \mathrm{eV}$. This explained easier removal of adsorbed species from the surface of amorphous alloys. The synergistic effect of Pt and Pd in alloys containing both the noble metals was demonstrated towards hydrogen oxidation reaction.
\end{abstract}

Fuel cells offer very high energy density among energy storage/conversion devices and are classified primarily based on their electrolyte or operation temperature ${ }^{1}$. Proton exchange membrane fuel cells (PEMFCs) are particularly attractive because they use hydrogen as fuel and operate at low temperatures $\left(50\right.$ to $\left.100^{\circ} \mathrm{C}\right)$. PEMFCs have emerged as a promising power source for transportation and portable energy storage and are likely to replace aging alkaline fuel-cell technology used in space shuttles ${ }^{2}$. However, one of the major bottlenecks in widespread use of PEMFCs has been the high cost of platinum group metals (PGM) used as catalysts. Pt- and Pd-based alloys including $\mathrm{Pt}-\mathrm{Ru}^{3}, \mathrm{Pt}-\mathrm{Sn}^{4}, \mathrm{Pt}_{-} \mathrm{Pd}^{5}, \mathrm{Pd}-\mathrm{Co}^{6}, \mathrm{Pd}-\mathrm{Au}^{7}, \mathrm{Pt}-\mathrm{Ru}-\mathrm{Mo}^{8}$ and $\mathrm{Pt}-\mathrm{Ru}-\mathrm{Ni}{ }^{9}$ have shown significantly higher electro-catalytic activity in both acidic and alkaline media compared to pure noble metal catalysts, allowing for reduced PGM loading. This has been attributed to the reduction in binding energy when the noble metals are alloyed with more oxophilic elements. Nevertheless, it should be noted that either too strong or too weak M-H ( $\mathrm{M}$ stands for metal surface) binding energy may result in poor catalytic behavior ${ }^{10}$. Furthermore, there is limited understanding and open questions related to the mechanism of oxidation/reduction and its relationship with electronic characteristics such as binding energy and work function (WF) ${ }^{11}$. According to the free energy of activation $\left(\Delta \mathrm{G}^{*}\right)$ for proton $\left(\mathrm{H}^{+}\right)$reduction, work function maybe directly correlated with the strength of $\mathrm{M}-\mathrm{H}$ bond. However, the reported trends are inconsistent or even contradictory ${ }^{12,13}$.

A major concern in PEMFCs is the degradation and dissolution of catalysts and carbon support under fuel cell operating conditions ${ }^{14}$, which determines a fuel cell performance in addition to catalyst chemistry. The majority of investigations on electrocatalysts have been limited to crystalline materials ${ }^{5,15,16}$. Only recently, bulk metallic glasses (BMGs) have attracted attention as highly active electro-catalysts owing to the high density of low-coordination sites on their surface, metastable amorphous structure, and high durability ${ }^{17-20}$. However, the effect of different amorphous chemistries on catalytic activity is not well understood and has not been reported. Catalytic reactions mainly consist of diffusion, adsorption, and desorption of chemical species along with charge transfer process. Work function (WF), which is the minimum energy required for removing an electron from a material's surface, plays a key role in the charge transfer process and shown to be correlated with catalytic activity $^{21,22}$. Scanning kelvin probe (SKP) may be used for measuring the contact potential difference (CPD) 
(a)

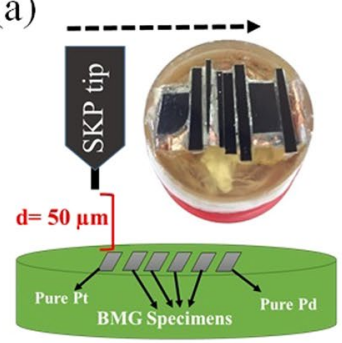

(b)

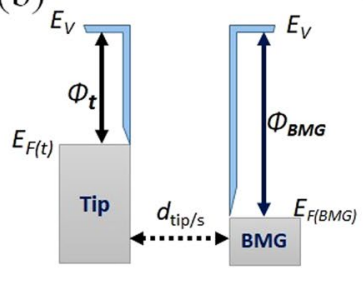

(c)

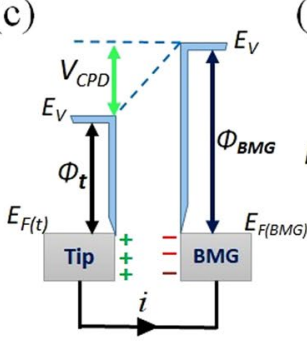

(d)

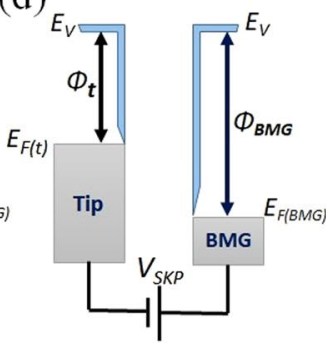

Figure 1. (a) The experimental setup and a schematic showing the array of amorphous alloys and pure Pt and Pd mounted side by side in a non-conductive resin. Energy level diagram of tip and substrate (BMG) when: (b) there is no electrical contact between the tip and substrate; (c) tip and the substrate are connected electrically while a contact potential difference $\left(\mathrm{V}_{\mathrm{CPD}}\right)$ is generated; and $(\mathbf{d})$ an external electrical bias is applied to nullify $\mathrm{V}_{\mathrm{CPD}}$, which is the SKP potential $\left(\mathrm{V}_{\text {skp }}\right) . \mathrm{E}_{\mathrm{v}}$ is the vacuum energy level, and $\mathrm{E}_{\mathrm{F}(\mathrm{t})}$ and $\mathrm{E}_{\mathrm{F}(\mathrm{BMG})}$ are Fermi levels of the tip and the BMG, respectively.

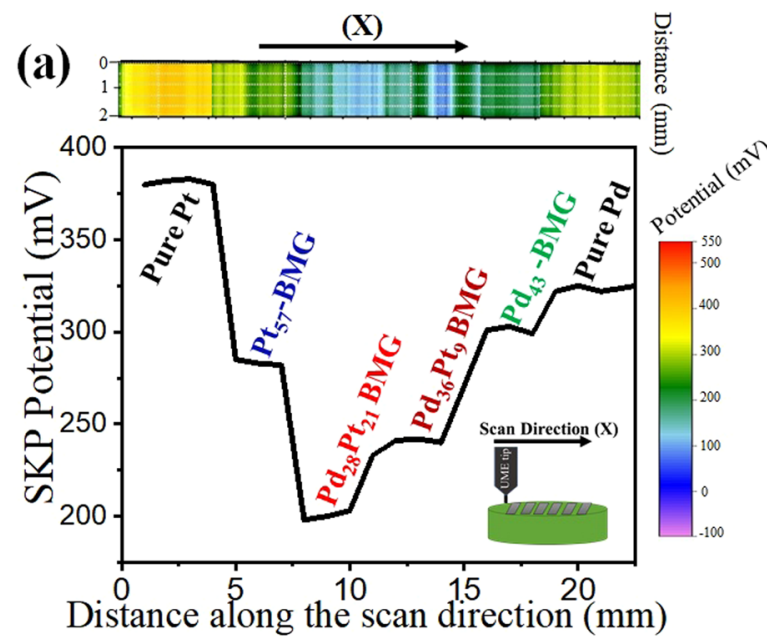

(b)

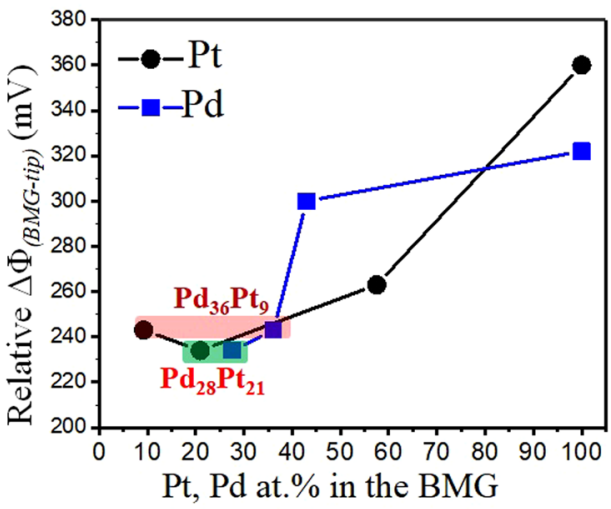

Figure 2. (a) SKP map/line scan of the BMGs along with pure Pt and Pd measured over an area of $2 \mathrm{~mm} \times 25 \mathrm{~mm}$ with a tungsten micro tip and the inset showing tip scanning direction over the array of amorphous alloys; (b) Relative work function difference of the BMGs as a function of Pt and Pd content with alloys containing both Pd and Pt marked with two separate boxes.

to generate high-resolution maps of work function or potential distribution ${ }^{23,24}$. Metal-catalyzed reaction rates depend exponentially on catalyst work function and referred to as electrochemical promotion of heterogeneously catalyzed (EPOC) reactions ${ }^{25}$. Furthermore, an inverse correlation between electrocatalytic behavior of polycrystalline Pt-based nanoparticles with the work function has been recently shown for oxygen reduction ${ }^{26}$. Combining SKP with in-situ electroanalytical techniques such as scanning electrochemical microscopy (SECM) ${ }^{27}$, may provide valuable insights into the underlying correlation between electronic and electro-catalytic characteristics of recently developed metallic glasses. Here, we report on the electro-catalytic activity of a series of Pd- and Pt-based metallic glasses using SECM and SKP for hydrogen oxidation reaction (HOR). SKP analysis was utilized for fundamental understanding of the role of electronic structure on electrochemical reactivity of the amorphous alloys. Synergistic effects of Pt/Pd toward HOR were shown for alloys containing both the noble metals.

\section{Results and Discussion}

The experimental setup and a schematic showing the array of amorphous alloys and pure Pt and Pd mounted side by side in a non-conductive resin are shown in Fig. 1(a). The tip was moved laterally over the surface of the specimen at a fixed distance of $50 \mu \mathrm{m}$ from the surface. Energy diagrams of the tungsten tip and BMG substrate separated at a certain distance $\left(d_{t i p / s}\right)$ are shown schematically in Fig. 1(b). The vacuum levels are the same while the Fermi levels are different for each materia ${ }^{28}$. When the tip and BMG sample are connected electrically, electron flow results in Fermi energy alignment and the system reaches equilibrium. However, a contact potential difference $\left(\mathrm{V}_{\mathrm{CPD}}\right)$ is formed between the tip and sample as shown in Fig. 1(c). The external opposite potential $\left(\mathrm{V}_{\mathrm{SKP}}\right)$ that nullifies $\mathrm{V}_{\mathrm{CPD}}$ (Fig. 1(d)) is proportional to the relative work function difference between the tungsten tip and BMG sample $\left(\mathrm{V}_{\mathrm{SKP}} \sim \Phi_{\mathrm{BMG}}-\Phi_{\mathrm{tip}}\right.$, in which $\Phi$ represents the work function).

SKP analysis was performed with a constant tip to specimen distance of $50 \mu \mathrm{m}$. The potential map and a single line scan of $\mathrm{V}_{\mathrm{SKP}}$ are shown in the Fig. 2(a). Positive values for the BMGs indicate their higher work function 
(a)

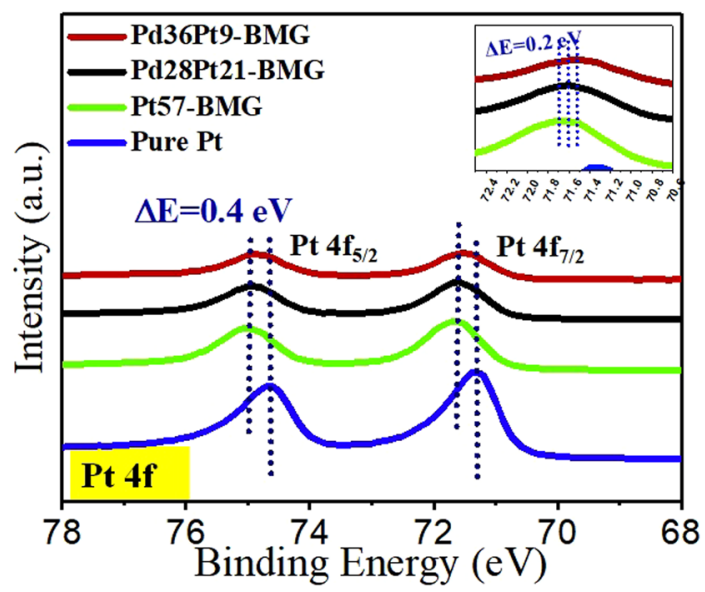

(b)

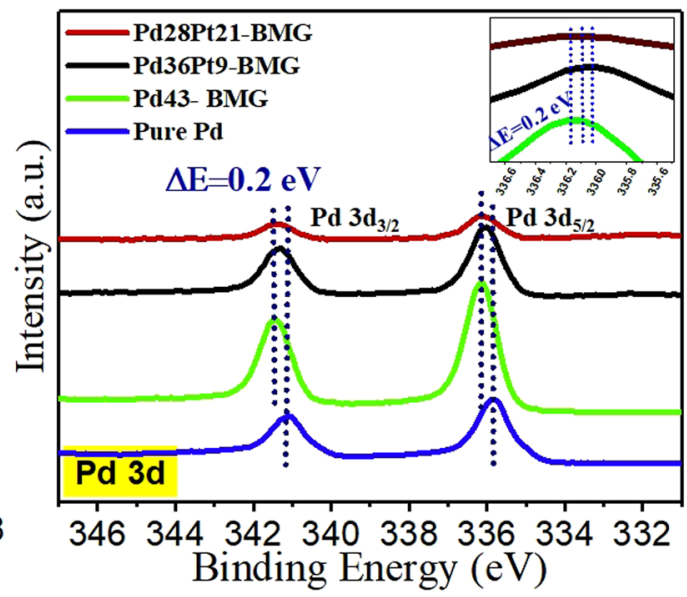

Figure 3. XPS spectra of (a) Pt $4 \mathrm{f}$ and (b) Pd 3d for the BMGs and pure Pt and Pd with the insets showing close-up view for peak positions in the amorphous alloys.

compared to tungsten $\left(\mathrm{V}_{\mathrm{CPD}}=\frac{\Phi_{\text {sample }}-\Phi_{\text {tip }}}{-e}\right)$. Pure Pt showed the highest work function followed by pure Pd and the amorphous alloys. The BMGs with higher fraction of noble metal showed higher work function. A roughly linear correlation between composition and work function has been reported for binary alloys of $\mathrm{AgAu}^{29}, \mathrm{PtRh}$ and $\mathrm{NiCu}^{30}$, showing an increasing trend with increase in the fraction of higher work function element. A similar trend was observed for the BMGs, as shown in Fig. 2(b). The alloys containing both Pt and Pd showed the lowest work function values, $\sim 150 \mathrm{mV}$ lower SKP potential compared to pure Pt. The rate of metal-catalyzed reactions in solid oxide fuel cells was shown to depend exponentially on average catalyst WF over a wide range of work functions $(0.3-1 \mathrm{eV})^{31}$. In the present study, WF for all BMGs was found to be lower compared to pure Pd and Pt. Higher electronic conductivity results in higher reaction rates over the catalyst surface due to easier electron transfer ${ }^{32}$. It has been reported that the work function of contaminated Ni films decreased noticeably with hydrogen adsorption on its surface which resulted in increase of conductivity ${ }^{33}$. Similarly, the ability of Pt-based nanoparticle catalysts to activate molecular oxygen has recently been shown to have an inverse correlation with $\mathrm{WF}^{26}$. As mentioned in the Materials and Methods section, surface roughness does not affect the work function values from SKP measurement because of surface topography correction. A high resolution topography history of the samples was initially recorded using constant height mode of the SKP microscope. The results were calibrated using the topography history to ensure that they were attributed only to the work function difference between the tip and the sample. The average surface roughness $\left(\mathrm{R}_{\mathrm{a}}\right)$ was calculated using Scanning Probe Microscopy to be $322.5 \pm 20.5 \mathrm{~nm}$ for all specimens.

To determine the possible correlation between lower work function of BMGs and their binding energies, the chemical valence state of the samples were obtained using XPS. The recorded Pt $4 \mathrm{f}$ and Pd $3 \mathrm{~d}$ core levels are

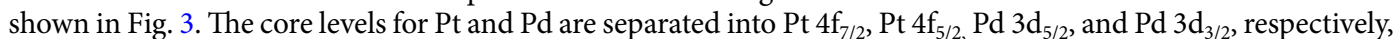
due to spin orbital splitting. The binding energy (BE) values at $71.3 \mathrm{eV}$ and $74.6 \mathrm{eV}$ correspond to $\mathrm{Pt} 4 \mathrm{f}_{7 / 2}$ and $\mathrm{Pt}$ $4 \mathrm{f}_{5 / 2}$, respectively, which are attributed to $\mathrm{Pt}^{\circ}$. The absence of other $\mathrm{Pt}$ valence states such as $\mathrm{Pt}^{2+}$ indicates that $\mathrm{Pt}$ is not present in the form of oxide or hydroxide on the surface, but in its zero-valent state. Interestingly, the $\mathrm{BE}$ of $\mathrm{Pt}$ for the $\mathrm{Pt}_{57}-\mathrm{BMG}$ showed a positive shift of $+0.4 \mathrm{eV}$ with respect to pure $\mathrm{Pt}$. The change in $\mathrm{BE}$ of $\mathrm{Pt}$ in the BMGs is likely related to the difference in electronegativity of the alloying elements $(\mathrm{Cu}, \mathrm{Ni}$ and $\mathrm{P})$. Moreover, it has been shown that the shift in $\mathrm{BE}$ is typically correlated to the change in $d$-band center, Fermi energy, and work function $^{34}$. The lower work function for the BMGs correspond to the positive shift of Pt bond strength in these metallic glasses. The upshift of bond strength in Pd- and Pt-based metallic glasses is indicative of a downshift in $d$-band center ${ }^{34}$. Any shift in $d$-band center for the Pt surface would result in a surface core-level shift in the same direction $^{35}$. The reduction in density of states at the Fermi level due to electron transfer from less electronegative elements to Pt or Pd has been reported to reduce the bond strength of Pt and adsorbed chemical species, leading to improved electro-catalytic activity of Pt-M $(\mathrm{M}=\mathrm{Ru}, \mathrm{Sn})$ alloys $^{36}$. In the present study, the chemisorption of protons on the Pd- and Pt-based amorphous alloy surface would be weakened since a higher $d$-band center corresponds to weaker M-H bonding ${ }^{37}$. Majority of the Pt is present in zero-valent state for all the BMG specimens. This may result in enhanced catalytic activity as zero-valent Pt provides more active sites ${ }^{38}$. A small difference $(\sim 0.2 \mathrm{eV})$ in Pt BE is seen among the different BMG compositions (the inset of Fig. 3(a)). A similar trend for $\mathrm{Pd}_{43}-\mathrm{BMG}$ was observed with respect to pure $\mathrm{Pd}$. The $\mathrm{BE}$ values at $335.8 \mathrm{eV}$ and $341.1 \mathrm{eV}$ correspond to $\mathrm{Pd}$ $3 \mathrm{~d}_{5 / 2}$ and $\mathrm{Pd} 3 \mathrm{~d}_{3 / 2}$, respectively, which are related to $\mathrm{Pd}^{\circ}$. A positive shift of $+0.4 \mathrm{eV}$ was observed for $\mathrm{Pd}^{\circ}$ in the $\mathrm{Pd}_{43}$-BMG. Higher BE of Pt and Pd in the Pt- and Pd-based BMGs may result in weakened chemisorption during catalysis. The binding energies of Pt and Pd for different BMG catalysts are summarized in Table 1. The BMGs showed higher binding energy of Pt and Pd in addition to reduced work function.

To investigate the electro-catalytic activity of the amorphous alloys with respect to pure noble metals, SECM imaging was employed in an electrolyte of $0.01 \mathrm{M} \mathrm{H}_{2} \mathrm{SO}_{4}$ mixed with argon saturated $0.1 \mathrm{M} \mathrm{Na}_{2} \mathrm{SO}_{4}$. Hydrogen 


\begin{tabular}{|c|c|c|c|c|c|}
\hline \multirow{2}{*}{\begin{tabular}{|l} 
Catalysts \\
Pure Pt
\end{tabular}} & \multicolumn{2}{|c|}{$\begin{array}{l}\text { Binding energy }(\mathrm{eV}) \\
\text { Pt } 4 \mathrm{f}_{7 / 2} \mathbf{4 f _ { 5 / 2 }}\end{array}$} & \multicolumn{2}{|c|}{$\mathbf{P d} 3 d_{5 / 2} 3 d_{3 / 2}$} & \multirow{2}{*}{$\begin{array}{l}\begin{array}{l}\Delta \mathrm{E}(\mathrm{eV})(\text { difference in binding } \\
\text { energy vs. pure } \mathrm{Pt} / \mathrm{Pd})\end{array} \\
- \\
\end{array}$} \\
\hline & 71.3 & 74.6 & - & - & \\
\hline $\mathrm{Pt}_{57}$-BMG & 71.7 & 75 & - & - & +0.4 \\
\hline $\mathrm{Pd}_{28} \mathrm{Pt}_{21}-\mathrm{BMG}$ & 71.6 & 74.9 & 336.1 & 341.4 & +0.3 \\
\hline $\mathrm{Pd}_{36} \mathrm{Pt}_{9}-\mathrm{BMG}$ & 71.5 & 74.8 & 336 & 341.3 & +0.2 \\
\hline $\mathrm{Pd}_{43}$-BMG & - & - & 336.2 & 341.5 & +0.4 \\
\hline Pure Pd & - & - & 335.8 & 341.1 & - \\
\hline
\end{tabular}

Table 1. Binding energies of Pt and Pd for the different metallic glass catalysts.

oxidation reaction was studied as it is the primary anodic reaction in PEMFC. Cyclic voltammetry at the Pt UME was recorded in bulk solution in the potential range of $-1.2 \mathrm{~V}$ to $+0.1 \mathrm{~V}$ (vs $\mathrm{Ag} / \mathrm{AgCl}$ ). At potentials higher than $-0.4 \mathrm{~V}$, the tip current approached zero (Fig. 4(a)). Since, hydrogen evolution reaction (HER) potential is roughly around $-0.25 \mathrm{~V}^{39}$, hydrogen would be oxidized in this potential range $(V>-0.4 \mathrm{~V})$. Due to large over-potential of Pt tip for HER, significant reduction of proton was not observed until the potential reached values below $-0.8 \mathrm{~V}$. The tip current reached a steady state in the potential range of $-0.9 \mathrm{~V}$ to $-1.2 \mathrm{~V}$ (vs. $\mathrm{Ag} / \mathrm{AgCl}$ ), with mass transport current reaching a value of $-900 \mathrm{nA}$. Further negative tip potentials $(V<-1.2 \mathrm{~V})$ led to the reduction of bulk water followed by formation of $\mathrm{H}_{2}$ bubbles. Approach curves were measured at various tip/substrate separations over the electrically conductive substrate and neighboring non-conductive resin. The tip and substrate were held fixed at $-1.2 \mathrm{~V}$ and open circuit potential (OCP), respectively. The measured current was normalized with respect to the tip current measured in bulk solution. A positive feedback was seen at the UME tip (Fig. 4(b)) and the $i_{\text {tip }} / i_{\text {bulk }}$ increased as the tip approached the BMG surface due to catalytic oxidation of locally generated hydrogen $\left(\mathrm{H}_{2}\right)$. In contrast, a negative feedback was observed when the Pt tip approached the nonconductive resin surface. The reactivity of BMGs towards HOR was imaged by performing cyclic voltammetry. Depending on the tip/substrate distance, the samples showed different feedback towards HOR (Fig. 4(c)). At large tip/sample separation (shown schematically as $d_{1}$ in Fig. $4(\mathrm{c})$ ), proton reduction occurred at the tip and there was no feedback from the substrate. With reduction of tip-substrate separation (shown schematically as $d_{2}$ in Fig. 4(c)), hydrogen oxidation from $\mathrm{Pt}_{57}$-BMG surface resulted in positive feedback. Hydrogen oxidation enhanced proton concentration in the vicinity of the Pt UME and increased the measured current at the tip as shown in Fig. 4(d). The recorded tip currents were normalized with respect to the measured values in bulk solution (Fig. 4(d)). A uniform tip response was observed when the tip was far from the substrate $(d>500 \mu \mathrm{m})$, with a nearly fixed current at the bulk diffusion-limited value $\left(\frac{i_{t i p}}{i_{\text {bulk }}}=1\right)$. At this separation, no feedback from the substrate was observed. The tip current significantly increased as the tip/substrate separation was reduced due to positive feedback from the BMG surface. Maximum tip current was recorded when the tip/substrate distance was $\sim 5 \mu \mathrm{m}$. About twelve-fold increase in the tip current was observed for $\mathrm{Pt}_{57}-\mathrm{BMG}$ at $5 \mu \mathrm{m}$ tip/sample separation as compared with bulk solution. The increase in tip current response was similar for $\mathrm{Pd}_{43}-\mathrm{BMG}$, but the magnitude was lower (nine-fold increase in this case as shown in Fig. 4(e)). Although the electronic properties of Pd and Pt are comparable, hydrogen adsorption is stronger on $\mathrm{Pd}$ as compared with $\mathrm{Pt}$, resulting in lower catalytic currents for $\mathrm{Pd}$ and its alloys ${ }^{10}$. The cyclic voltammetry plots for the other amorphous alloys were similar and are not shown.

To measure the kinetics of catalytic reaction, the Pt tip polarized at $-1.2 \mathrm{~V}$ was scanned over all the alloys at a fixed tip/substrate separation of $5 \mu \mathrm{m}$. No over-potential was applied to the catalysts during the experiments. The variation in Pt tip current is proportional to the catalytic rate constant of the amorphous alloys. More negative values correspond to higher reactivity of the substrate. The plotted SECM map and the corresponding Pt tip current line scan are shown in Fig. 5(a). The variation in UME tip current was solely from the difference in chemistry of the BMGs since all the alloys were fully amorphous and had the same surface finish. Pure Pt and Pd specimens showed lower catalytic reactivity towards HOR compared to the amorphous alloys. Both the $\mathrm{Pd}_{43}$ - and $\mathrm{Pt}_{57}-\mathrm{BMGs}$ exhibited higher activity compared to their pure counterparts, with the UME tip reduction current increase of $30 \mathrm{nA}$ and $20 \mathrm{nA}$, respectively. The amorphous alloys containing both Pd and Pt exhibited the highest activity towards HOR among the systems studied. Higher specific activity (kinetic current per unit surface area of a catalyst) has recently been shown for Pd-Pt nano-dendrites towards ORR, which was related to the preferential exposure of more active crystalline facets $(\mathrm{Pt}(111)$ is more favored in the presence of $\mathrm{Pd})$ on the Pt branches as compared with small $\mathrm{Pt}$ nanoparticles in $\mathrm{Pt} / \mathrm{C}^{40}$. This synergistic effect has been attributed to the modification of $\mathrm{Pt} d$-band center and weakening of electronic interaction between $\mathrm{Pt}$ atoms and oxygenated species. Most of the reports on synergistic effects of Pt/Pd towards different catalytic reactions have been attributed to crystallographic modification of Pt. However, $\mathrm{BMGs}$ have a homogenous amorphous structure without any crystalline facets ${ }^{41}$. The high density of low coordination sites in the amorphous alloys likely resulted in enhanced surface reations and higher catalytic activity ${ }^{42}$.

In order to evaluate the stability of the amorphous catalysts towards HOR, chronoamperometry was performed for all the samples. All the alloys reached steady-state current densities within 200 sec (Fig. 5(b)). However, the current densities for the amorphous alloys containing both Pd and Pt were significantly higher compared to others, which may be attributed to the synergistic effect between these elements. The trend in chronoamperometry results were along the same lines as the SECM activity map. Modification of electronic structure may account for the better catalytic performance of Pt/Pd-based BMGs. Work function values for BMGs containing both $\mathrm{Pd}$ and $\mathrm{Pt}$ were lower compared with $\mathrm{Pd}_{43}$ - and $\mathrm{Pt}_{57}$-based $\mathrm{BMGs}$, promoting easier electron transfer. This also explains the shift in binding energies to higher values reducing the chemisorption of absorbed species for Pt/Pd alloys ${ }^{34}$. 


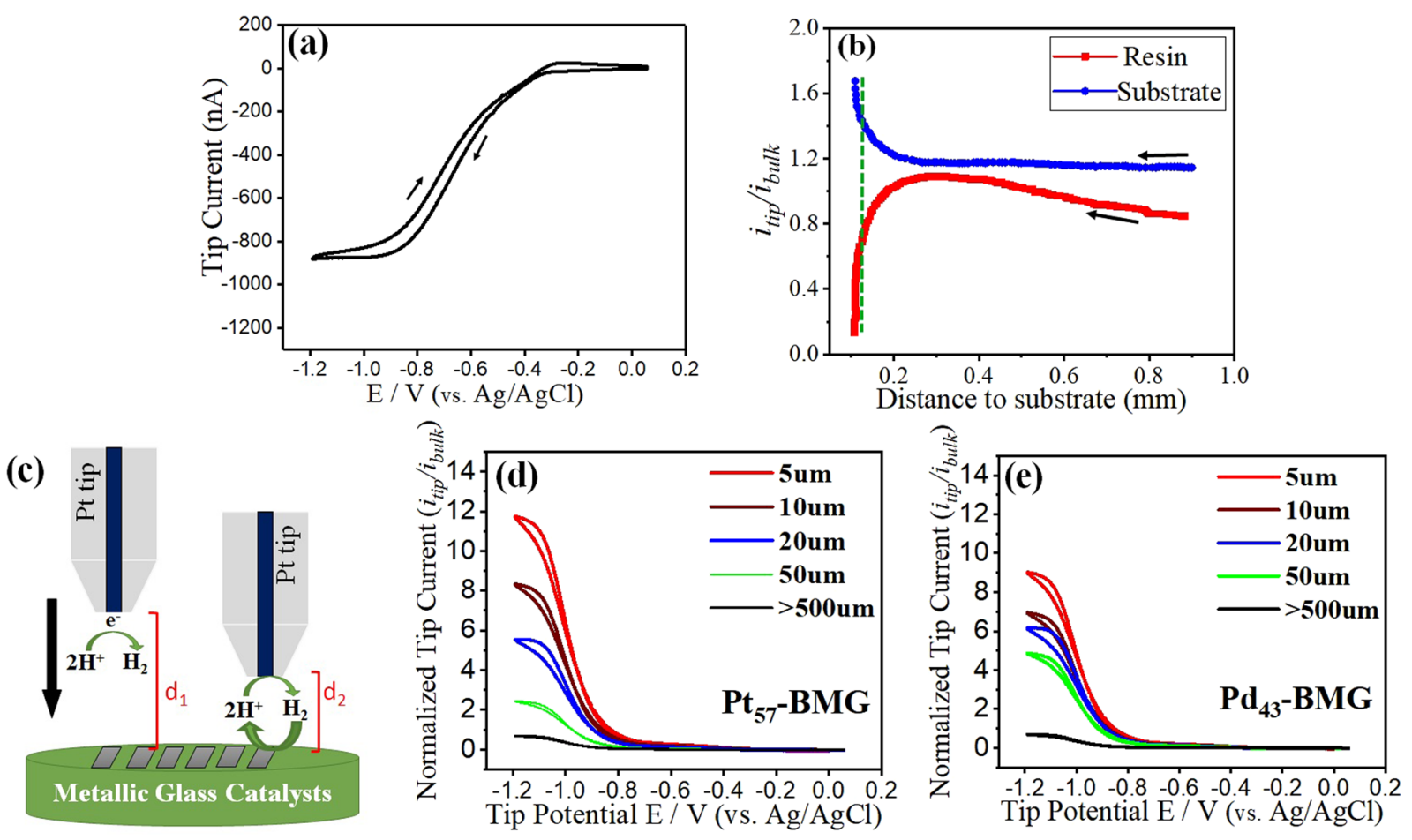

Figure 4. (a) Cyclic voltammogram of Pt microelectrode in $0.01 \mathrm{M} \mathrm{H}_{2} \mathrm{SO}_{4}+0.1 \mathrm{M} \mathrm{Na}_{2} \mathrm{SO}_{4}$ solution at a scan rate of $50 \mathrm{mV} / \mathrm{s}$ in bulk solution $(\mathrm{d}>500 \mu \mathrm{m})$; (b) Z-approach curves of Pt UME over $\mathrm{Pt}_{57}-\mathrm{BMG}$ and nonconductive resin, the dashed line shows the selected tip/substrate distance; (c) Schematic of the response of BMG substrate/SECM tip at various $d$ values, at $d_{1}$ the tip/substrate separation is too high for getting feedback from the substrate, while at $\mathrm{d}_{2}$ the substrate is close enough to the tip to oxidize protons; (d) Tip current normalized by the bulk value in $0.01 \mathrm{M} \mathrm{H}_{2} \mathrm{SO}_{4}+0.1 \mathrm{M} \mathrm{Na}_{2} \mathrm{SO}_{4}$ solution at various tip-substrate distances over $\mathrm{Pt}_{57}$ - $\mathrm{BMG}$. The tip potential was scanned between $-1.2 \mathrm{~V}$ and $0.1 \mathrm{~V}(\mathrm{vs} \mathrm{Ag} / \mathrm{AgCl}$ ) at $100 \mathrm{mV} / \mathrm{s}$, while the substrate was at OCP; (e) Tip current normalized by the bulk value in $0.01 \mathrm{M} \mathrm{H}_{2} \mathrm{SO}_{4}+0.1 \mathrm{M} \mathrm{Na}_{2} \mathrm{SO}_{4}$ solution at various tip-substrate distances over $\mathrm{Pd}_{43}$-BMG.

(a)

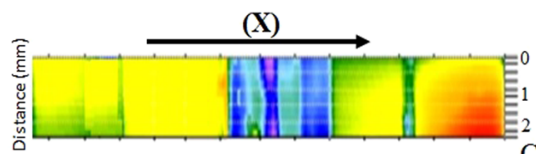

(b)

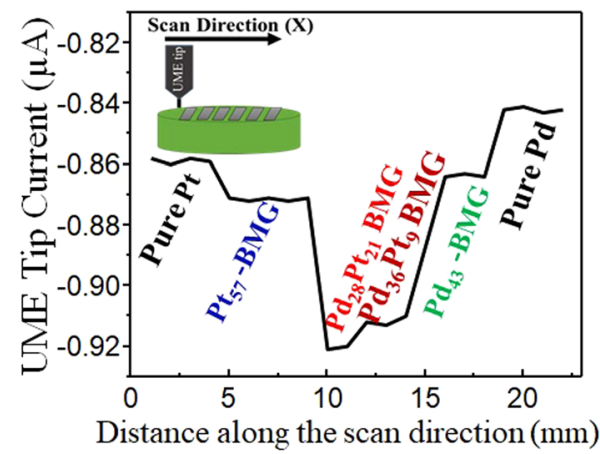

Current $(\mu \mathrm{A})$
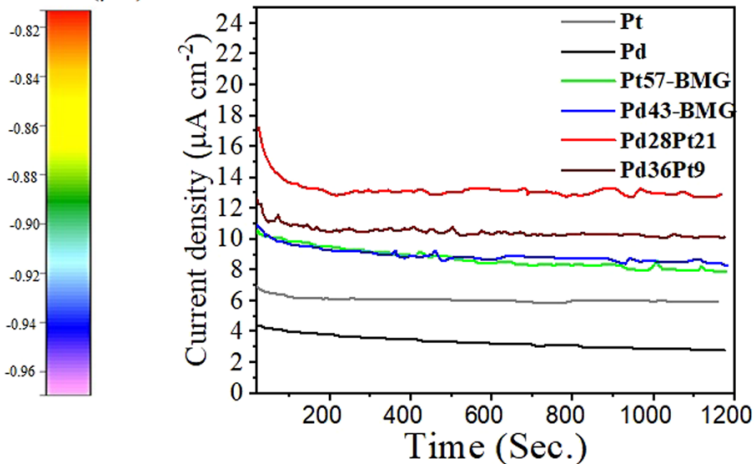

Figure 5. (a) Pt UME reduction current distribution map along with a single line scan over the BMGs in $0.01 \mathrm{M} \mathrm{H}_{2} \mathrm{SO}_{4}+0.1 \mathrm{M} \mathrm{Na}_{2} \mathrm{SO}_{4}$ solution at a fixed tip/substrate distance of $5 \mu \mathrm{m}$, the tip potential was held fixed at $-1.2 \mathrm{~V}$ (vs. $\mathrm{Ag} / \mathrm{AgCl}$ ), while the sample was at OCP; the inset shows the tip scanning direction over the array of amorphous alloys; (b) Chronoamperometric plots of the metallic glass catalysts and pure $\mathrm{Pt}$ and $\mathrm{Pd}$ at a potential of $-1100 \mathrm{mV}$ (vs $\mathrm{Ag} / \mathrm{AgCl}$ ) in $0.01 \mathrm{M} \mathrm{H}_{2} \mathrm{SO}_{4}+0.1 \mathrm{M} \mathrm{Na}_{2} \mathrm{SO}_{4}$.

\section{Conclusions}

Scanning electrochemical microscopy was utilized to evaluate the catalytic performance of several Pd-and Pt-based amorphous alloys towards hydrogen oxidation reaction, the main anodic reaction in PEM fuel cells. The metallic glasses showed higher catalytic activity compared to pure Pt and Pd, which was attributed to their 


\begin{tabular}{|l|l|l|l|l|}
\hline BMG Alloy & Composition & $\begin{array}{l}\mathbf{T}_{\mathbf{g}} \\
\left({ }^{(} \mathrm{C}\right)\end{array}$ & $\begin{array}{l}\mathrm{T}_{\boldsymbol{x}} \\
\left({ }^{\circ} \mathrm{C}\right)\end{array}$ & $\begin{array}{l}\Delta \mathrm{T} \\
\left(\boldsymbol{T}_{\boldsymbol{x}}-\boldsymbol{T}_{\boldsymbol{g}}\right)\end{array}$ \\
\hline $\mathrm{Pt}_{57}-\mathrm{BMG}$ & $\mathrm{Pt}_{57.5} \mathrm{Cu}_{14.7} \mathrm{Ni}_{5.3} \mathrm{P}_{22.5}$ & 235 & 315 & 80 \\
\hline $\mathrm{Pd}_{28} \mathrm{Pt}_{21} \mathrm{BMG}$ & $\mathrm{Pd}_{27.5} \mathrm{Pt}_{20.9} \mathrm{Cu}_{22.6} \mathrm{Ni}_{8.2} \mathrm{P}_{20.9}$ & 265 & 350 & 85 \\
\hline $\mathrm{Pd}_{36} \mathrm{Pt}_{9} \mathrm{BMG}$ & $\mathrm{Pd}_{36.1} \mathrm{Pt}_{9.2} \mathrm{Cu}_{25.1} \mathrm{Ni}_{9.2} \mathrm{P}_{20.3}$ & 310 & 380 & 70 \\
\hline $\mathrm{Pd}_{43}-\mathrm{BMG}$ & $\mathrm{Pd}_{43} \mathrm{Ni}_{10} \mathrm{Cu}_{27} \mathrm{P}_{20}$ & 310 & 390 & 80 \\
\hline
\end{tabular}

Table 2. The composition, glass transition temperature $\left(\mathrm{T}_{\mathrm{g}}\right)$, crystallization temperature $\left(\mathrm{T}_{\mathrm{x}}\right)$, and the difference between glass transition and crystallization temperatures $(\Delta \mathrm{T})$ for the BMGs.

relatively lower work function measured by scanning kelvin probe (SKP). The work function for the metallic glasses was lower by $75 \mathrm{mV}$ to $175 \mathrm{mV}$ compared to pure Pt. This resulted in higher catalytic activity for the amorphous alloys, which was attributed to the ease of charge transfer on the surface. The shift in Pt and Pd binding energies to higher values, as shown by XPS, supported the weakened chemisorption of adsorbed species and more enhanced catalysis. The alloys containing both Pt and Pd showed the highest catalytic activity towards HOR, attributed to the synergy between the two noble elements by electronic structure modification.

\section{Materials and Methods}

Materials. In this study, four different metallic glass systems were chosen: one Pt-based bulk metallic glass of composition $\mathrm{Pt}_{57.5} \mathrm{Cu}_{14.7} \mathrm{Ni}_{5.3} \mathrm{P}_{22.5}{ }^{43}$ (referred to as $\mathrm{Pt}_{57}-\mathrm{BMG}$ ), one Pd-based $\mathrm{BMG}$ of composition $\mathrm{Pd}_{43} \mathrm{Ni}_{10} \mathrm{Cu}_{27} \mathrm{P}_{20}{ }^{44}$ (referred to as $\mathrm{Pd}_{43}-\mathrm{BMG}$ ), and two recently developed BMGs containing both Pt and Pd, namely $\mathrm{Pd}_{27.5} \mathrm{Pt}_{20.9} \mathrm{Cu}_{22.6} \mathrm{Ni}_{8.2} \mathrm{P}_{20.9}$ (referred to as $\mathrm{Pd}_{28} \mathrm{Pt}_{21} \mathrm{BMG}$ ) and $\mathrm{Pd}_{36.1} \mathrm{Pt}_{9.2} \mathrm{Cu}_{25.1} \mathrm{Ni}_{9.2} \mathrm{P}_{20.3}$ (referred to as $\mathrm{Pd}_{36} \mathrm{Pt}_{9}$ $\mathrm{BMG}$ ). All the alloys were prepared in the form of amorphous rods by induction melting high purity starting elements in vacuum-sealed quartz tubes followed by water quenching molten samples after appropriate $\mathrm{B}_{2} \mathrm{O}_{3}$ fluxing. The glass transition $\left(\mathrm{T}_{\mathrm{g}}\right)$ and crystallization $\left(\mathrm{T}_{\mathrm{x}}\right)$ temperatures, measured using differential scanning calorimetry (DSC-Netzsch) with a heating rate of $20 \mathrm{~K} / \mathrm{min}$, are summarized in Table 2.

Pure crystalline Pd and Pt were used as reference catalysts. To analyze the surface chemical valence states of the BMG specimens, X-ray photoelectron spectroscopy (XPS-PHI 5000 Versaprobe) was done. The BMGs were then mounted in a hard resin side by side, with a conductive copper tape on the other side for electrochemical studies. The mounted specimens were polished to a $0.1 \mu \mathrm{m}$ surface finish followed by Vibromet polishing for $24 \mathrm{~h}$ in $0.04 \mu \mathrm{m}$ colloidal silica suspension. To remove any contamination from the surface, the samples were cleaned ultrasonically in acetone for $10 \mathrm{~min}$ followed by isopropanol for $15 \mathrm{~min}$ and subsequently washed with distilled water. The roughness of the surface was measured using high resolution scanning probe microscopy (SPM).

Electrochemical measurements. To measure relative work function of the specimens, SKP analysis was performed in dry lab air. A pure tungsten microprobe $(150 \mu \mathrm{m}$ in diameter) was used as reference electrode vibrating at a frequency of $80 \mathrm{~Hz}$ with an amplitude of $30 \mu \mathrm{m}$ normal to the surface. A backing potential was applied to minimize the capacitance between probe and working electrode. A constant tip to substrate distance of $50 \mu \mathrm{m}$ was used for the experiment. A high resolution topography history of the samples was initially recorded using constant height mode (CHM) of the SKP microscope (VersaSCAN-Princeton Applied Research) with step size of $20 \mu \mathrm{m}$ over an area of $2 \mathrm{~mm} \times 25 \mathrm{~mm}$. The SKP potential map was recorded over all the samples with a fixed step size, potential gain, time constant and sensitivity. Finally, the results were calibrated using the topography history to ensure that they were attributed only to the work function difference between the tip and the amorphous alloys.

For measuring the electrocatalytic activity of the BMGs, high resolution SECM (VersaSCAN-AMETEK) was used in redox competition mode. The key components of the system included a potentiostat (VersaSTAT 3F) coupled with a positioning system, an ultramicroelectrode (UME) and BMG sample as the working electrode. The tip/sample separation was optimized at $5 \mu \mathrm{m}$, and kept constant for all catalytic reaction studies using software based tilt correction. The catalytic performance measurement was done over an area of $2 \mathrm{~mm} \times 25 \mathrm{~mm}$, with step size of $10 \mu \mathrm{m}$ at a fixed tip/substrate separation of $5 \mu \mathrm{m} . \mathrm{Ag} / \mathrm{AgCl} / 3 \mathrm{M} \mathrm{KCl}(\mathrm{E}=0.196 \mathrm{~V}$ vs SHE$)$ and a $\mathrm{Pt}$ wire were used as the reference and counter electrodes, respectively. A Pt UME with a radius of $10 \mu \mathrm{m}$ encased in borosilicate glass tube was used as SECM tip. The RG ratio (where RG is the ratio of insulating sheath radius divided by the Pt tip radius) of the probe was $\sim 10$ with a disk-in-plane geometry. The UME was polished gently with Alumina slurry, carefully washed with distilled water, and pre-treated with potential cycling in $0.1 \mathrm{M} \mathrm{H}_{2} \mathrm{SO}_{4}$ before use. All cyclic voltammetry experiments were performed at a potential sweep rate of $50 \mathrm{mVs}^{-1}$ and room temperature.

For determining the optimum distance between the tip and substrate, approach curves were plotted using $\mathrm{Pt}$ $\mathrm{UME}$ as the working electrode, while the insulator resin and conductive BMG alloys were employed as substrates. The distance at which the tip current changed to $75 \%$ of bulk solution current was chosen as the desired tip/ substrate separation. All electrochemical experiments were conducted in aqueous solution containing $\mathrm{H}_{2} \mathrm{SO}_{4}$ and $\mathrm{Na}_{2} \mathrm{SO}_{4}$, deaerated with argon gas prior to measurement. To investigate the stability of the alloys towards $\mathrm{HOR}$, chronoamperometry was performed in a three electrode cell set up with $\mathrm{Pt}$ wire and $\mathrm{Ag} / \mathrm{AgCl}$ electrodes as counter and reference, respectively, at a scan rate of $10 \mathrm{mV} / \mathrm{s}$ for $1200 \mathrm{sec}$. The measured current was normalized by the surface area of the specimens.

Data Availability

All data generated or analysed during this study are included in this published article. 


\section{References}

1. Bard, A. Inner-Sphere Heterogeneous Electrode Reactions. Electrocatalysis and Photocatalysis: The Challenge. J. Am. Chem. Soc. 132, 7559-7567 (2010).

2. P. Loyselle \& K. Prokopius Teledyne Energy Systems, Inc., Proton Exchange Member (PEM) Fuel Cell Engineering Model Powerplant. NASA (2011).

3. Schmidt, T. et al. PtRu Alloy Colloids as Precursors For Fuel Cell Catalysts- A Combined XPS, AFM, HRTEM, and RDE Study. J. Electrochem. Soc. 145, 925-931 (1998).

4. Neto, A., Dias, R., Tusi, M., Linardi, M. \& Spinace, E. Electrooxidation of Methanol and Ethanol Using PtRu/C, PtSn/C And $\mathrm{PtSnRu} / \mathrm{C}$ Electrocatalysts Prepared by an Alcohol-Reduction Process. J. Power Sources 166, 87-91 (2007).

5. Chen, Z., Waje, M., Li, W. \& Yan, Y. Supportless Pt and PtPd Nanotubes as Electrocatalysts for Oxygen-Reduction Reactions. Angew Chem. Int. Ed. Engl. 46, 4060-4063 (2007).

6. Bianchini, C. \& Shen, P. Palladium-based Electrocatalysts for Alcohol Oxidation in Half Cells and in Direct Alcohol Fuel Cells. Chem. Rev. 109, 4183-4206 (2009).

7. Cheng, F. et al. Synergistic effect of Pd-Au bimetallic surfaces in Au-covered Pd nanowires studied for ethanol oxidation. Electrochim. Acta 55, 2295-2298 (2010).

8. Wang, Z., Yin, G. \& Lin, Y. Synthesis and Characterization of PtRuMo/C Nanoparticle Electrocatalyst for Direct Ethanol Fuel Cell. J. Power Sources 170, 242-250 (2007).

9. Liang, Y. et al. Synthesis and Structure-Activity Relationship Exploration of Carbon-Supported PtRuNi Nanocomposite as a COTolerant Electrocatalyst fFor Proton Exchange Membrane Fuel Cells. J. Phys. Chem. B 110, 7828-7834 (2006).

10. Shao, M. Palladium-based electrocatalysts for hydrogen oxidation and oxygen reduction reactions. J. Power Sources 196, 2433-2444 (2011).

11. Zeradjanin, A. R. et al. Balanced Work Function as a Driver for Facile Hydrogen Evolution Reaction -Comprehension and Experimental Assessment of Interfacial Catalytic Descriptor. Phys. Chem. Chem. Phys. 19, 17019-17027 (2017).

12. Nørskov, J. K. et al. Trends in the Exchange Current for Hydrogen Evolution. J. Electrochem. Soc. 152(3), J23-J26 (2005).

13. Trasatti, S. Work Function, Electronegativity, and Electrochemical Behaviour of Metals. J. Electroanal. Chem. Interfacial Electrochem 39, 163-184 (1972).

14. Wang, J. et al. Effect of Carbon Black Support Corrosion on The Durability of Pt/C Catalyst. J. Power Sources 171(2), 331-339 (2007).

15. Kang, Y. et al. Design of Pt-Pd Binary Superlattices Exploiting Shape Effects and Synergistic Effects for Oxygen Reduction Reactions. J. Am. Chem. Soc. 135, 42-45 (2013).

16. Yang, H., Alonso-Vante, N., Leger, J.-M. \& Lamy, C. Tailoring, Structure, and Activity of Carbon-Supported Nanosized Pt-Cr Alloy Electrocatalysts for Oxygen Reduction in Pure and Methanol-Containing Electrolytes. J. Phys. Chem. B 108, 1938-1947 (2004).

17. Baiker, A. Metallic Glasses in Heterogeneous Catalysis. Faraday Discuss. Chem. Soc. 87, 239-251 (1989).

18. Carmo, M. et al. Bulk Metallic Glass Nanowire Architecture for Electrochemical Applications. ACS Nano 5(4), 2979-2983 (2011).

19. Mukherjee, S. et al. Tunable Hierarchical Metallic-Glass Nanostructures. Adv. Funct. Mater. 23, 2708-2713 (2013).

20. Mukherjee, S. et al. Palladium nanostructures from multi-component metallic glass. Electrochim. Acta 74, 154-150 (2012).

21. Kim, J. H., Ishihara, A., Mitsushima, S., Kamiya, N. \& Ota, K.-I. Catalytic activity of titanium oxide for oxygen reduction reaction as a non-platinum catalyst for PEFC. Electrochim. Acta 52(7), 2492-2497 (2007).

22. H. S. Casalongue et al. Direct observation of the oxygenated species during oxygen reduction on a platinum fuel cell cathode. Nat. Commun. (4), 2817 (2013).

23. Ritty, B., Wachtel, F., Manquenouille, R., Ott, F. \& Donnet, A. J. B. Conditions Necessary to Get Meaningful Measurements from the Kelvin Method. J. Phys. E 15, 310-317 (1982).

24. Rohwerder, M. \& Turcu, F. High-Resolution Kelvin Probe Microscopy in Corrosion Science: Scanning Kelvin Probe Force Microscopy (SKPFM) versus Classical Scanning Kelvin Probe (SKP). Electrochim. Acta 53(2), 290-299 (2007).

25. Imbihl, R. Electrochemical Promotion of Catalytic Reactions. Prog. Surf. Sci. 85, 241-278 (2010).

26. Duch, J. et al. Thermal oxygen activation followed by in situ work function measurements over carbon-supported noble metal-based catalysts. Int. J. Hydrogen Energy 44(31), 16648-16656 (2019).

27. Bard, A. J., Denuault, G., Friesner, R. A., Dornblaser, B. C. \& Tuckerman, L. S. Scanning Electrochemical Microscopy: Theory and Application of the Transient (Chronoamperometric) SECM Response. Anal. Chem. 63, 1282-1288 (1981).

28. Melitz, W., Shen, J., Kummel, A. C. \& Lee, S. Kelvin Probe Force Microscopy and Its Application. Surface Science Reports 66, 1-27 (2011).

29. Fain, J. S. C. \& Mcoavid, J. M. Work-Function Variation with Alloy Composition: Ag-Au. Phys. Rev. B 9, 5099-5107 (1974).

30. Ishii, R., Matsumura, K., Sakai, A. \& Sakata, T. Work Function of Binary Alloys. Appl. Surf. Sci. 169-170, 658-661 (2001).

31. Vayenas, C. G., Bebelis, S. \& Ladas, S. Dependence of Catalyic Rates on Catalyst Work Function. Nature 343, 625-627 (1990).

32. Shao, Y., Sui, J., Yin, G. \& Gao, Y. Nitrogen-doped carbon nanostructures and their composites as catalytic materials for proton exchange membrane fuel cell. Appl. Catal., B 79(1), 89-99 (2008).

33. Sachtler, W. M. H. Work Function and Electrical Conductivity of Hydrogen Covered Nickel Films. The Effect of Contamination. J. Chem. Phys. 25(4), 751-759 (1956).

34. Zhao, Q. et al. Synthesis of Highly Active and Dual-Functional Electrocatalysts for Methanol Oxidation and Oxygen Reduction Reactions. Appl. Surf. Sci. 89, 181-189 (2016).

35. Hammer, B. \& Nørsko, J. K. Theoretical Surface Science and Catalysis-Calculations and Concepts. Adv. Catal. 45, 71-129 (2000).

36. Ishikawa, Y., Liao, M.-S. \& Cabrera, C. R. Oxidation of methanol on platinum, ruthenium and mixed Pt- M metals (M=Ru, Sn): a theoretical study. Surf. Sci. 463, 66-80 (2000).

37. Hu, Y., Wu, P., Yin, Y., Zhang, H. \& Cai, C. Effects of Structure, Composition, and Carbon Support Properties on The Electrocatalytic Activity of Pt-Ni-Graphene Nanocatalysts for The Methanol Oxidation. Appl. Catal. B 111-112, 208-217 (2012).

38. Cai, B. et al. Function-Led Design of Aerogels: Self-Assembly of Alloyed PdNi Hollow Nanospheres for Efficient Electrocatalysis. Angew. Chem.Int. Ed. 45, 13101-13105 (2015).

39. Shah, B. C. \& Hillier, A. C. Imaging the Reactivity of Electro-oxidation Catalysts with the Scanning Electrochemical Microscope. J. Electrochem. Soc. 147(8), 3043-3048 (2000).

40. Lim, B. et al. Pd-Pt Bimetallic Nanodendrites with High Activity for Oxygen Reduction. Science 324, 1302-1305 (2009).

41. Mridha, S., Jaeger, D. L., Aroraa, H. S., Banerjee, R. \& Mukherjee, S. Evolution of Atomic Distribution during Devitrification of Bulk Metallic Glass Investigated By Atom Probe Microscopy. Mater. Lett. 158(1), 99-103 (2015).

42. Deng, J.-F., Li, H. \& Wang, W. Progress in design of new amorphous alloy catalysts. Catal. Today 51(1), 113-125 (1999).

43. Schroers, J. \& Johnson, W. L. Highly Processable Bulk Metallic Glass-forming Alloys in the Pt-Co-Ni-Cu-P System. Appl. Phys. Lett. 84, 3666-3668 (2004).

44. Nishiyama, N. \& Inoue, A. Supercooling Investigation and Critical Cooling Rate for Glass Formation in Pd-Cu-Ni-P Alloy. Acta Mater. 47, 1487-1495 (1999).

\section{Acknowledgements}

This work was partly supported by funding from the National Science Foundation (NSF) under Grant Number 1561886 (NSF-CMMI). Any opinions, findings, and conclusions expressed in this paper are those of the authors and do not necessarily reflect the views of the National Science Foundation (NSF). 


\section{Author Contributions}

V.H. performed the SECM/SKP, XPS experiments and electrochemical characterization, discussed the results, and wrote the paper. S.M. designed and supervised the project and wrote the paper.

\section{Additional Information}

Competing Interests: The authors declare no competing interests.

Publisher's note: Springer Nature remains neutral with regard to jurisdictional claims in published maps and institutional affiliations.

(c) (i) Open Access This article is licensed under a Creative Commons Attribution 4.0 International License, which permits use, sharing, adaptation, distribution and reproduction in any medium or format, as long as you give appropriate credit to the original author(s) and the source, provide a link to the Creative Commons license, and indicate if changes were made. The images or other third party material in this article are included in the article's Creative Commons license, unless indicated otherwise in a credit line to the material. If material is not included in the article's Creative Commons license and your intended use is not permitted by statutory regulation or exceeds the permitted use, you will need to obtain permission directly from the copyright holder. To view a copy of this license, visit http://creativecommons.org/licenses/by/4.0/.

(C) The Author(s) 2019 